\title{
Butyrate induces profound changes in gene expression related to multiple signal pathways in bovine kidney epithelial cells Robert $\mathrm{W} \mathrm{Li}^{* 1}$ and CongJun $\mathrm{Li}^{2}$
}

\author{
Address: ${ }^{1}$ Bovine Functional Genomics Laboratory, Animal and Natural Resources Institute, United States Department of Agriculture-Agricultural \\ Research Service, Beltsville, MD 20705, USA and ${ }^{2}$ Growth Biology Laboratory, Animal and Natural Resources Institute, United States Department \\ of Agriculture-Agricultural Research Service, Beltsville, MD 20705, USA \\ Email: Robert W Li* - rli@anri.barc.usda.gov; CongJun Li - cli@anri.barc.usda.gov \\ * Corresponding author
}

Published: 14 September 2006

BMC Genomics 2006, 7:234 doi:10.1/86/147|-2164-7-234
Received: 07 June 2006

Accepted: 14 September 2006

This article is available from: http://www.biomedcentral.com/I47/-2164/7/234

(C) $2006 \mathrm{Li}$ and Li; licensee BioMed Central Ltd.

This is an Open Access article distributed under the terms of the Creative Commons Attribution License (http://creativecommons.org/licenses/by/2.0), which permits unrestricted use, distribution, and reproduction in any medium, provided the original work is properly cited.

\begin{abstract}
Background: Global gene expression profiles of bovine kidney epithelial cells regulated by sodium butyrate were investigated with high-density oligonucleotide microarrays. The bovine microarray with 86,191 distinct 60 mer oligonucleotides, each with 4 replicates, was designed and produced with Maskless Array Synthesizer technology. These oligonucleotides represent approximately 45,383 unique cattle sequences.

Results: 450 genes significantly regulated by butyrate with a median False Discovery Rate (FDR) $=0 \%$ were identified. The majority of these genes were repressed by butyrate and associated with cell cycle control. The expression levels of 30 selected genes identified by the microarray were confirmed using real-time PCR. The results from real-time $P C R$ positively correlated $(R=0.867)$ with the results from the microarray.

Conclusion: This study presented the genes related to multiple signal pathways such as cell cycle control and apoptosis. The profound changes in gene expression elucidate the molecular basis for the pleiotropic effects of butyrate on biological processes. These findings enable better recognition of the full range of beneficial roles butyrate may play during cattle energy metabolism, cell growth and proliferation, and possibly in fighting gastrointestinal pathogens.
\end{abstract}

\section{Background}

The most common short-chain fatty acids (SCFA) are natural microbial fermentation products in the gastrointestinal tract. SCFA, including propionic, butyric and valeric acids, each with three, four and five carbons, respectively, contribute to the energy balance of all mammalian species $[1,2]$. The major sources of these carbohydrates are hemicelluloses and fiber, which consists of plant cell wall polysaccharides such as cellulose and pectins [1]. In ruminants, SCFA are a major energy source and contribute up to $70 \%$ of their energy requirements [2]. Beyond their nutritional impact, SCFA, especially butyrate, have a multitude of cellular regulatory effects that modulate cell differentiation, proliferation, and motility. All three major components of SCFA induce apoptosis and inhibit cell proliferation, however, butyrate has the most potent effect $[3,4]$. Roles for butyrate have been established in cell differentiation, proliferation, motility and in particular induction of cell cycle arrest and apoptosis [5-7]. Apoptosis is a genetically regulated cellular suicide mechanism that plays a crucial role in development and in the defense of homeostasis of animals [8]. The mechanism(s) by 
which butyrate induces cellular differentiation and suppresses growth has not been elucidated. Similarly, the mechanism through which butyrate and other short-chain fatty acids induce the cell cycle regulatory and apoptotic effects and the mechanism by which the decision between cell death and survival is arbitrated are poorly understood [9-12].

In a previous study [13], potential biological roles of butyrate were investigated using the established MadinDarby bovine kidney epithelial cell line (MDBK). The study focused on determining whether normal bovine cells in a standard cell culture condition were sensitive to the growth inhibitory effects of butyrate. The data suggested that sodium butyrate (SB) could induce apoptosis and cell cycle arrest in MDBK cells. Up to $38 \%$ of cells became apoptotic after 24 hours of treatment with $10 \mathrm{mM}$ of butyrate. Butyrate also blocked the surviving cells at two distinct stages, G1 and M/G2. However, more studies are needed to better understand the relationship between butyrate and alterations in the expression of genes involved in cell cycle, apoptosis, and transcriptional regulation. Recent advances in high-throughput genomic tools such as microarray technology allowed us to examine the genome-wide effects of sodium butyrate on MDBK cells.

\section{Results \\ Butyrate Induces Cell Cycle Arrest and Hyperacetylation of Histone 3 in MDBK Cells}

We previously reported that butyrate induced cell cycle arrest in MDBK cells [13]. Prior to microarray analysis, the butyrate induced cell cycle arrest was reconfirmed. As shown in Figure 1, after butyrate treatment for $24 \mathrm{~h}$, cell population profiles changed significantly. In the surviving cell population there was a significant increase in the number of cells in G1 (cells with 2C DNA contents) whereas those in $\mathrm{S}$ phase (cells falling between the $2 \mathrm{C}$ and 4C DNA contents) were decreased. This result confirmed our prior observation that cells were arrested at the G1/S boundary and DNA replication was blocked by the butyrate treatment. We also confirmed accumulation of acetylated histone 3 (H3) due to the butyrate treatment (Fig. 2). H3 acetylation was selected as the marker for the accumulation of acetylated histones because $\mathrm{H} 3$ is one of the core histones (H2A, H2B, H3, and H4), and is highly conserved across a wide range of organisms. The antibody against the acetyl $\mathrm{H} 3$ (lys18) is also readily available commercially. To determine whether these biochemical attributes of butyrate were also observed in MDBK cells, two specific antibodies, the monoclonal antibody against the acetyl $\mathrm{H} 3$ and the monoclonal antibody against acetyl-phospho $\mathrm{H} 3$, were used to evaluate the histone deacetylase inhibitory activity of butyrate. Histone deacetylase (HDAC) inhibitors induce the hyperacetylation of nucleosomal histones. Evidence suggested that H3 phosphorylation is restricted to a small fraction of highly acetylated $\mathrm{H} 3$ histones. $\mathrm{H} 3$ phosphorylation is cell cycle dependent and may be associated with induced FOS and MYC oncogenes. No evidence indicates $\mathrm{H} 3$ phosphorylation directly results from HADC inhibitory activities. As shown in Fig. 2, butyrate treatment induced not only accumulation of hyperacetylation of H3 (Lys18) but also phosphor (Ser10)-acetyl (Lys9) H3. The quantified relative densities from the Western Blot show approximately a 2-fold increase of acetylated H3 protein and 2-fold increase of phosphor-acetyl H3 (Fig. 2B). Therefore it is reasonable to assume the increase detected by the antibody against phosph(Ser10)-Acetyl (lys9)-H3 is mostly due to the acetylation of $\mathrm{H} 3$ induced by butyrate.

\section{Butyrate Induces Profound Changes in Gene Expression in MDBK Cells}

In our previous study [13] and prior to the current microarray experiment, we monitored butyrate induced cell death and cell cycle arrest in MDBK cells in a time/dosedependent manner using flow cytometry and Western blotting. For the purpose of this investigation and for determining the differential gene expression induced by butyrate, we selected a single dose proven to be able to generate maximum biological impacts in cell cycle arrest. Due to research budget constraints, we selected only a single time point as the initial global expression screening. We intend to verify the genes identified with the microarray in a time/dose-dependent manner using real-time RTPCR in subsequent studies. We identified 450 genes significantly regulated by sodium butyrate at a very stringent false discovery rate $($ FDR $)=0 \%$ (see Additional file 1$)$. However, when relaxing the stringency threshold to FDR $=10 \%$, which should still be acceptable in most cases, there were 3662 genes significantly regulated (3662/ $45383=8 \%$, data not shown). This percentage was consistent with a previous report [6] in which the authors used cDNA microarrays consisting of $\sim 8000$ sequences to demonstrate that approximately $7 \%$ of sequences assayed exhibited alteration by butyrate in human colon carcinoma cells.

\section{Cell Cycle Control}

The single largest category of genes regulated by butyrate (103) was cell cycle control related (Table 1). Butyrate repressed the vast majority of these genes including cyclins, cyclin-dependent kinases, histone deacetylases, helicases, chromosomal structure proteins as well as kinesins. Ubiquitin conjugating enzyme E2 C was also down-regulated. However, Max interacting protein 1 (MXI1) was upregulated 12.6 -fold by butyrate.

\section{Apoptosis and Extracellular Matrix}

Fourteen genes related to apoptosis and extracellular matrix (ECM) were significantly regulated by butyrate 


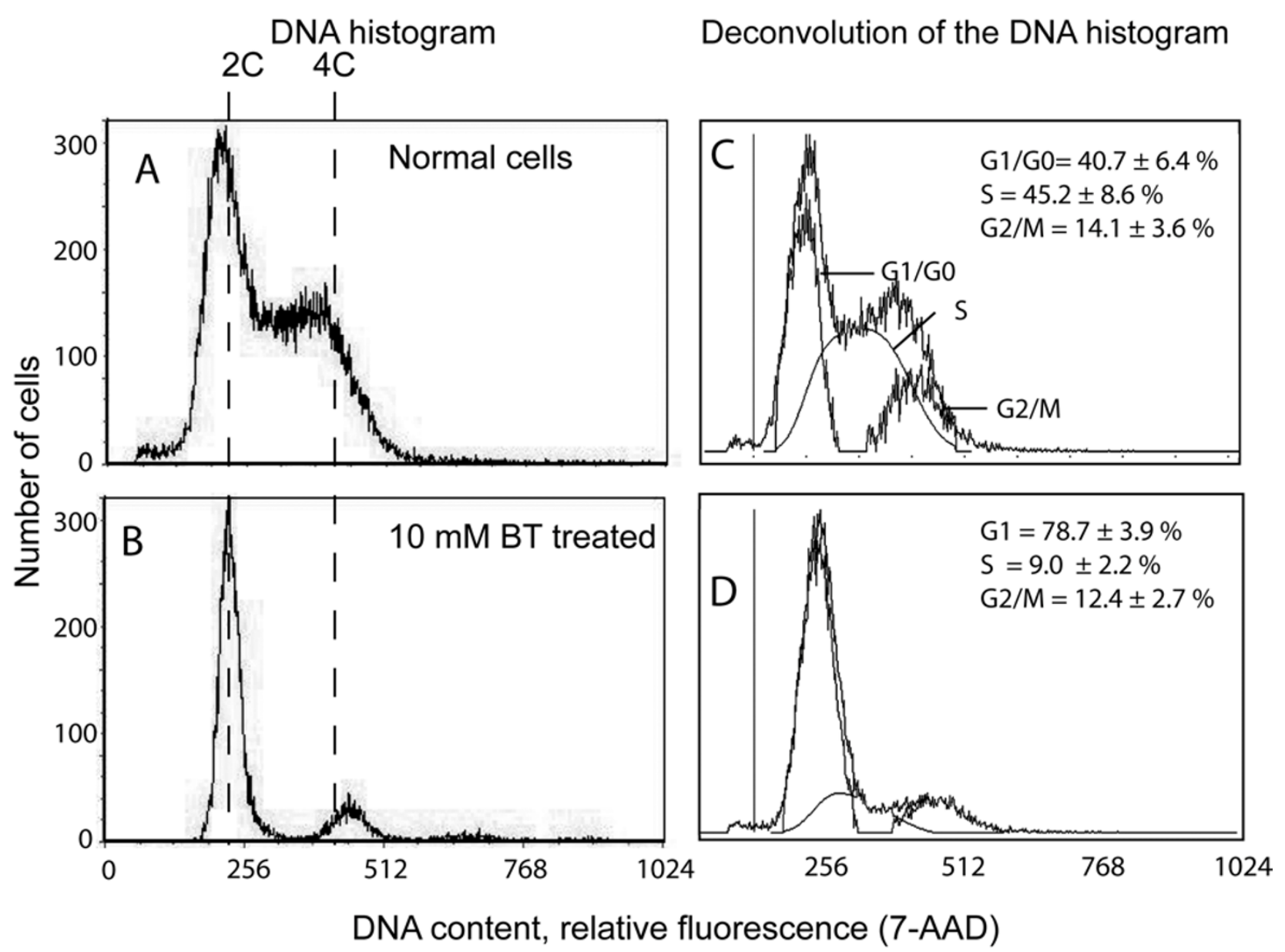

Figure I

Cell cycle progressions determined by flow cytometry. Histogram plot of flow cytometry analysis of A: control cells; B: the cells treated by $10 \mathrm{mM}$ sodium butyrate. Deconvolution of the DNA histogram using automated cell cycle analysis with 'Cylchred' software of C: control cells; and D: the cells treated by $10 \mathrm{mM}$ sodium butyrate. Insert: Mean \pm SEM ( $n=3$ per treatment; **: $P$ < 0.0 I. GI/G0: cells in GI/G0 cell cycle phases; S: cells in S cell cycle phase; M/G2: cells in M/G2 cell Cycle phases). $2 \mathrm{C}$ and 4C: two and four copies of DNA content respectively.

(Table 2). Generally, butyrate induced pro-apoptotic genes and repressed anti-apoptotic genes. Inhibin, beta A (INHBA) and adrenomedullin were among the induced genes while apoptosis inhibitors such as survivin and FAIM were down-regulated. Interestingly, Insulin-like growth factor 2 (IGF2) was up-regulated while IGF binding proteins 4 and 6 were down-regulated. Collagens, such as COL5A2 and COL3A1, and extracellular matrix protein Spondin 1 were repressed by butyrate while tissue inhibitor of metalloproteinase 2 (TIMP2) was significantly up-regulated.

\section{Real-Time RT PCR}

Thirty genes that represent different expression levels and functional classes were selected for real-time RT-PCR con- firmation (Table 3). The real-time PCR data generally confirmed the microarray analysis. Linear regression analysis demonstrated a strong positive correlation between the two technological platforms with $\mathrm{R}=0.867$.

\section{Discussion}

Cell cycle regulatory and apoptotic effects of butyrate and other short-chain fatty acids at the cellular and molecular levels in normal bovine cells have not been studied thus far but would serve as a principle launch point to validate the need for further study of these phenomena in cattle. Furthermore, utilization of particular signaling pathways in regulating cellular function or inducing gene expression appears to be dependent on, among other factors, the type of stimulus and cell examined. In our previous study, 


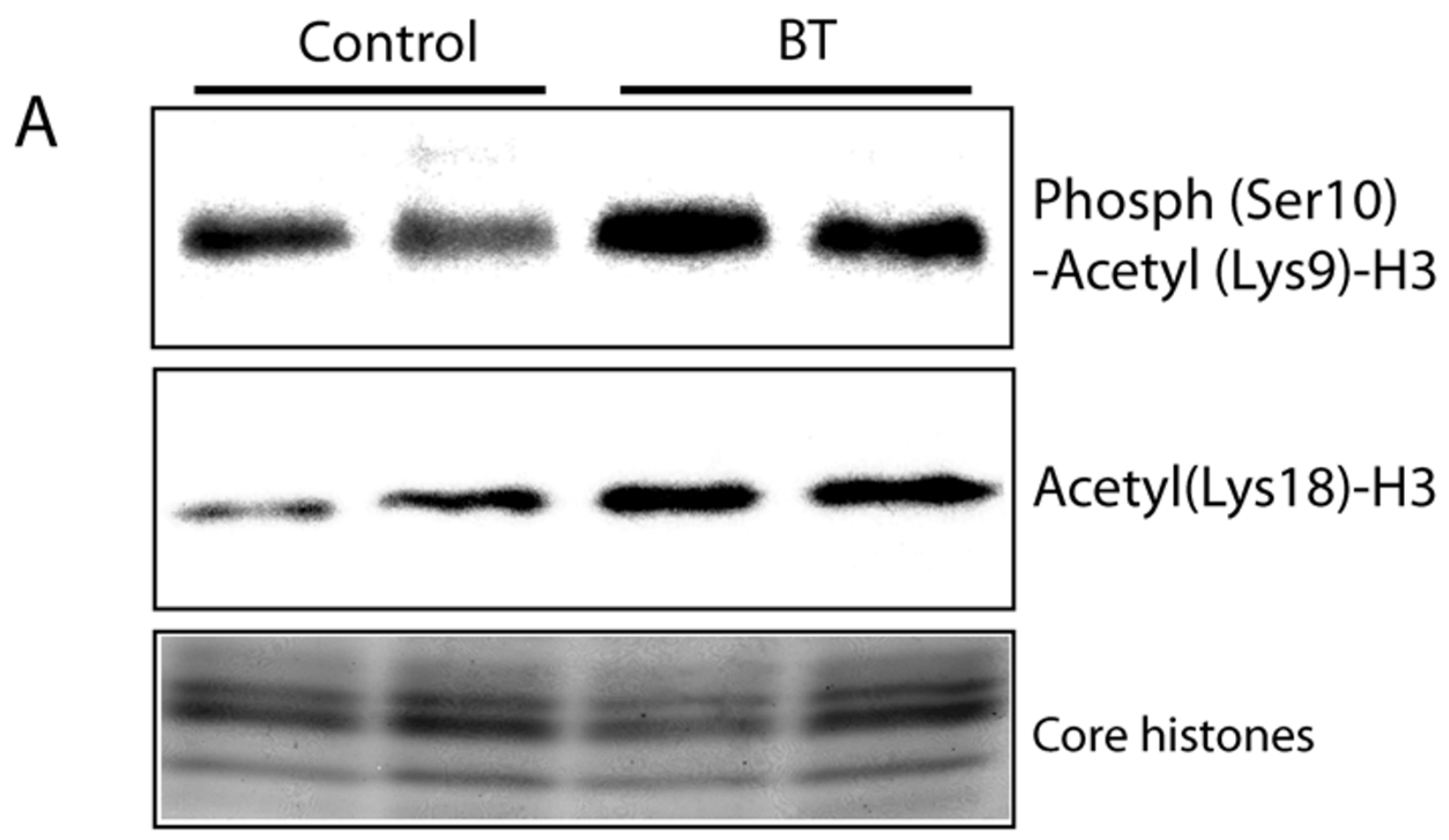

B

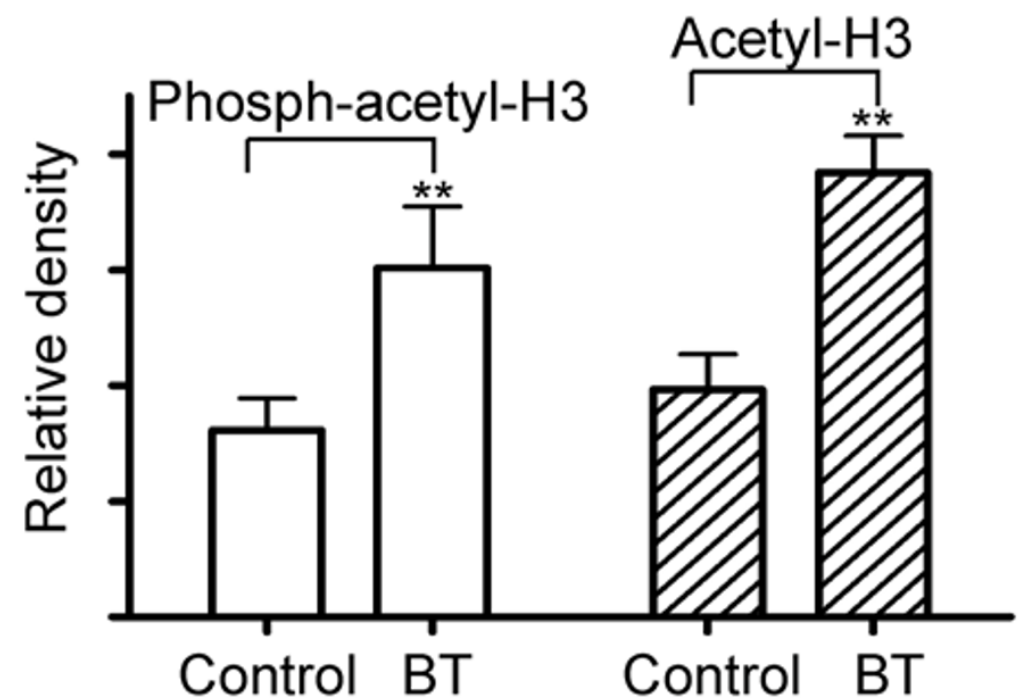

Figure 2

Butyrate induced hyperacetylation of histone $3(\mathrm{H} 3)$. This figure is representative of three experiments $(n=3)$. A: Protein from different samples was separated by SDS PAGE on two identical 4 to $20 \%$ polyacrylamide gradient gels. One gel was stained with SimpleBlue (Invitrogen) and one was transferred to a membrane for Western blotting with monoclonal anti- acetyl-phospho $\mathrm{H} 3$ and anti- acetyl H3 antibodies; B: Western Blots from three experiments were quantified with NIH Image software. The relative densities were measured and corrected with the protein density. $\mathrm{H} 3$ : histone 3 . **: $P<0.0 \mathrm{I}$. 
Table I: Cell cycle-related genes significantly regulated by butyrate.

\begin{tabular}{|c|c|c|c|}
\hline Accession & Annotation & Fold & q-value*(\%) \\
\hline TC265I70 & Aurora kinase $\mathrm{A}$ (AURKA) & 0.17 & 0 \\
\hline TC266385 & Aurora kinase $B(A \cup R K B)$ & 0.18 & 0 \\
\hline TC27806I & Aurora-A kinase interacting protein (AURKAIPI) & 0.19 & 0 \\
\hline TC281252 & BUBI budding uninhibited by benzimidazoles I homolog (BUBI) & 0.10 & 0 \\
\hline TC28I450 & BUBI budding uninhibited by benzimidazoles I homolog beta (BUBIB) & 0.06 & 0 \\
\hline TC280420 & CDC28 protein kinase regulatory subunit 2 & 0.02 & 0 \\
\hline TC292959 & CDC2LI & 0.04 & 0 \\
\hline TC293208 & CDC45 cell division cycle 45 -like & 0.09 & 0 \\
\hline TC278776 & Cell division cycle $2, \mathrm{GI}$ to $\mathrm{S}$ and $\mathrm{G} 2$ to $\mathrm{M}$ (CDC2) & 0.12 & 0 \\
\hline TC285500 & Cell division cycle $25 \mathrm{~A}(\mathrm{CDC} 25 \mathrm{~A})$ & 0.11 & 0 \\
\hline TC271610 & Cell division cycle 25B isoform 3 & 0.14 & 0 \\
\hline TC2947I3 & Cell division cycle 2-related & 0.16 & 0 \\
\hline TC278478 & Cell division cycle and apoptosis regulator I & 0.17 & 0 \\
\hline TC294633 & Cell division cycle associated 2 (CDCA2) & 0.08 & 0 \\
\hline TC292945 & Cell division cycle associated 8 & 0.17 & 0 \\
\hline TC26374I & Cell division cycle protein 20 homolog (p55CDC) & 0.10 & 0 \\
\hline CK97586I & Centromere protein $\mathrm{F}(350 / 400 \mathrm{kD})$ & 0.06 & 0 \\
\hline TC261I65 & Centromere protein-A (CENP-A) & 0.09 & 0 \\
\hline TC267900 & Centromeric protein E (CENP-E protein) & 0.11 & 0 \\
\hline TC279457 & CHKI checkpoint homolog & 0.16 & 0 \\
\hline TC293183 & Chromatin assembly factor I subunit A (CAF-I) & 0.20 & 0 \\
\hline TC268367 & Chromobox protein homolog 5 & 0.10 & 0 \\
\hline TC297649 & Chromodomain helicase DNA binding protein 3 & 0.14 & 0 \\
\hline TC265382 & Chromosome condensation protein $\mathrm{G}$ & 0.06 & 0 \\
\hline TC262952 & Cyclin A2 & 0.17 & 0 \\
\hline TC265945 & Cyclin BI (CCNBI) & 0.06 & 0 \\
\hline TC278429 & Cyclin B2 (CCNB2) & 0.22 & 0 \\
\hline TC262075 & Cyclin GI & 0.07 & 0 \\
\hline TC262855 & Cyclin-dependent kinase 4 & 0.15 & 0 \\
\hline TC265450 & Cyclin-dependent kinase inhibitor $2 \mathrm{C}$ & 0.22 & 0 \\
\hline TC278545 & Cyclin-dependent kinases regulatory subunit I (CKS-I) & 0.09 & 0 \\
\hline TC2843I7 & Defective in sister chromatid cohesion homolog I & 0.06 & 0 \\
\hline TC290880 & Deoxythymidylate kinase (thymidylate kinase) (LOC506946) & 0.15 & 0 \\
\hline TC273I70 & Discs large homolog 7 (DLG7) & 0.22 & 0 \\
\hline TC265245 & DNA directed RNA polymerase III polypeptide D & 0.12 & 0 \\
\hline TC28436I & DNA helicase (Blooms syndrome protein, RecQ protein-like 3) & 0.11 & 0 \\
\hline TC267I67 & DNA mismatch repair protein Msh3 (mut S homolog 3) & 0.24 & 0 \\
\hline TC278497 & DNA polymerase epsilon pI7 subunit gene & 0.03 & 0 \\
\hline TC279954 & DNA polymerase, alpha 2 (70kD subunit)(POLA2) & 0.11 & 0 \\
\hline CK945922 & DNA repair and recombination protein RAD54-likex & 0.06 & 0 \\
\hline TC282404 & DNA repair protein RAD5I homolog I & 0.11 & 0 \\
\hline TC290487 & E2F transcription factor 4 & 0.11 & 0 \\
\hline TC282I53 & Establishment of cohesion I homolog 2 & 0.13 & 0 \\
\hline TC265789 & Extra spindle poles like I (ESPLI) & 0.08 & 0 \\
\hline TC291293 & flap structure-specific endonuclease I (FENI) & 0.18 & 0 \\
\hline TC266990 & G-2 and S-phase expressed I & 0.23 & 0 \\
\hline TC270253 & GAJ protein (MNDI) & 0.07 & 0 \\
\hline TC292293 & General transcription factor IIIC, polypeptide 2, beta II0kDa & 0.24 & 0 \\
\hline BG688435 & $\mathrm{H} / \mathrm{ACA}$ ribonucleoprotein complex subunit 4 (Dyskerin, $\mathrm{DKCI}$ ) & 0.11 & 0 \\
\hline TC269917 & Helicase, lymphoid-specific & 0.13 & 0 \\
\hline TC267482 & Histone deacetylase 8 & 0.15 & 0 \\
\hline TC276662 & Histone H2A.Z & 0.08 & 0 \\
\hline
\end{tabular}


Table I: Cell cycle-related genes significantly regulated by butyrate. (Continued)

\begin{tabular}{|c|c|c|c|}
\hline TC272233 & Huntingtin interacting protein 2 (HIP2) & 0.25 & 0 \\
\hline TC267608 & Inner centromere protein & 0.11 & 0 \\
\hline TC279078 & Katanin p80 (KATNBI) & 0.16 & 0 \\
\hline TC295304 & Kinesin family member II & 0.23 & 0 \\
\hline TC294618 & Kinesin family member 14 & 0.20 & 0 \\
\hline TC267353 & Kinesin family member $20 \mathrm{~A}$ & 0.12 & 0 \\
\hline TC260588 & Kinesin-like protein KIF22 & 0.09 & 0 \\
\hline TC29|455 & Kinesin-like protein KIF23 (Mitotic kinesin-like protein I) & 0.07 & 0 \\
\hline TC278220 & Kinesin-like protein KIF2C (Mitotic centromere-associated kinesin) & 0.19 & 0 \\
\hline TC266372 & Kinetochore associated 2 & 0.15 & 0 \\
\hline TC284307 & Lamin BI (LMNBI) & 0.05 & 0 \\
\hline TC277820 & MAD2 mitotic arrest deficient-like I & 0.07 & 0 \\
\hline TC288554 & Max interacting protein I (MXII) & 12.55 & 0 \\
\hline TC261106 & MCM4 (CDC2I homolog) DNA replication licensing factor & 0.14 & 0 \\
\hline TC26498I & Minichromosome maintenance deficient 3 (MCM3) & 0.10 & 0 \\
\hline TC277221 & Minichromosome maintenance deficient 5 (MCM5, CDC46 homolog) & 0.17 & 0 \\
\hline TC265572 & Minichromosome maintenance deficient 6 (MCM6) & 0.09 & 0 \\
\hline TC26358I & Minichromosome maintenance protein 2 & 0.14 & 0 \\
\hline TC290639 & Minichromosome maintenance protein 3 associated protein & 0.16 & 0 \\
\hline TC293069 & Mitotic spindle associated protein p 26, MAPI 26 & 0.04 & 0 \\
\hline TC298939 & M-phase phosphoprotein I (mitotic kinesin-like protein, MPHOSPHI) & 0.13 & 0 \\
\hline TC260429 & MutS homolog 6 & 0.21 & 0 \\
\hline TC2665I3 & NEK2 (NIMA-related protein kinase 2) & 0.13 & 0 \\
\hline TC278195 & Nuclear ubiquitous casein and cyclin-dependent kinases substrate $(\mathrm{PI})$ & 0.19 & 0 \\
\hline TC279654 & Nucleolar and spindle associated protein I & 0.08 & 0 \\
\hline TC274682 & Nucleolin & 0.10 & 0 \\
\hline TC293949 & Origin recognition complex subunit I & 0.23 & 0 \\
\hline TC28194I & PDZ-binding kinase (PBK) & 0.15 & 0 \\
\hline TC278800 & pescadillo homolog I, containing BRCT domain (PESI) & 0.17 & 0 \\
\hline TC289876 & Proliferating cell nuclear antigen (PCNA) & 0.09 & 0 \\
\hline TC263003 & Proliferation-associated 2G4 & 0.16 & 0 \\
\hline TC276620 & Proteasome (prosome, macropain) 28 subunit, alpha & 0.21 & 0 \\
\hline TC260258 & Proteasome subunit, beta type 8 (PSMB8) & 0.14 & 0 \\
\hline TC292683 & Protein C20orfI72 (C20orfI72) & 0.06 & 0 \\
\hline TC300533 & Protein regulator of cytokinesis I & 0.07 & 0 \\
\hline TC279370 & Protein regulator of cytokinesis I (PRCI) & 0.11 & 0 \\
\hline TC282034 & RAD5I associated protein I (RAD5IAPI) & 0.21 & 0 \\
\hline TC28058I & Replication factor C (activator I) 3 (RFC3) & 0.19 & 0 \\
\hline TC265859 & Replication factor C (activator I) 4 (RFC4) & 0.03 & 0 \\
\hline TC263936 & Ribonucleoside-diphosphate reductase M2 chain (RRM2) & 0.17 & 0 \\
\hline TC275004 & Scaffold attachment factor B2 & 0.20 & 0 \\
\hline TC266542 & Sin3 associated polypeptide p30 (SAP30) & 0.22 & 0 \\
\hline TC282970 & SMC4 structural maintenance of chromosomes 4-like I (SMC4LI) & 0.13 & 0 \\
\hline TC290192 & Spindle pole body component 24 (kinetochore protein Spc24) & 0.09 & 0 \\
\hline TC281963 & Spindle pole body component 25 (kinetochore protein Spc25) & 0.14 & 0 \\
\hline TC279I53 & Topoisomerase (DNA) II binding & 0.05 & 0 \\
\hline TC278044 & Transcription elongation regulator I & 0.09 & 0 \\
\hline TC28I73I & Transducin (beta)-like IX-linked receptor I (TBLIXRI) & 0.08 & 0 \\
\hline TC277942 & Ubiquitin-conjugating enzyme E2 C (Ubiquitin-protein ligase C) & 0.14 & 0 \\
\hline TC280380 & Weel-like protein kinase & 0.16 & 0 \\
\hline TC279802 & XPMC2 prevents mitotic catastrophe 2 homolog & 0.21 & 0 \\
\hline
\end{tabular}

\footnotetext{
* q-value is a percentage of a gene identified by chance as being significant.
} 
Table 2: Apoptosis- and ECM-related genes significantly regulated by butyrate

\begin{tabular}{|c|c|c|c|}
\hline Accession & Annotation & Fold & q-value (\%) \\
\hline CK975939 & Tissue factor pathway inhibitor-2 (TFPI2) & 0.07 & 0 \\
\hline TC26670I & Fas apoptotic inhibitory molecule (FAIM) & 0.07 & 0 \\
\hline CK965I46 & Collagen alpha 2(V) chain precursor (COL5A2) & 0.12 & 0 \\
\hline TC28II70 & Tissue factor pathway inhibitor precursor (TFPI) & 0.12 & 0 \\
\hline TC281607 & Baculoviral IAP repeat-containing 5 (BIRC5) & 0.16 & 0 \\
\hline TC261916 & procollagen, type III, alpha I (COL3AI) & 0.16 & 0 \\
\hline TC279824 & spondin I(SPONI) & 0.19 & 0 \\
\hline TC289874 & Insulin-like growth factor-binding protein 6 (IGFBP6) & 0.2 & 0 \\
\hline TC275I 58 & Insulin-like growth factor-binding protein 4 (IGFBP4) & 0.21 & 0 \\
\hline TC265483 & Programmed cell death II(PDCDII) & 0.27 & 0 \\
\hline TC27674I & Insulin-like growth factor 2 (IGF2) & 6.5 & 0 \\
\hline TC265993 & Inhibin, beta A (INHBA) & 9.48 & 0 \\
\hline TC277385 & Adrenomedullin (ADM) & 12.47 & 0 \\
\hline TC260960 & Tissue inhibitor of metalloproteinase 2 (TIMP2) & 14.05 & 0 \\
\hline
\end{tabular}

an important question asked and answered was whether normal bovine cells in a standard cell culture condition are sensitive to the growth inhibitory effects of butyrate[13]. In this follow-up study, we utilize microarray technique to examine the genome-wide effects of sodium butyrate on MDBK cells as an important component of our efforts to understand the mechanisms of this phenomenon. Our data presented in this report indicate that the effects of butyrate are mediated through coordinated changes in gene expression that are the outcome of interactions between transduction pathways. We identified 450 genes significantly regulated by sodium butyrate at a very stringent false discovery rate $(F D R)=0 \%$. However, since many of the genes have no direct links to the cell cycle arrest or apoptosis, their involvement in these biological effects certainly warrants more investigation. Therefore, instead of speculating, our discussion is concentrated primarily in cell cycle and apoptosis.

Sodium butyrate (SB) exerts a very broad range of effects on many biological pathways via its inhibitory ability on HDAC. SB is a potent inducer of a G1 cell cycle arrest. It also provokes apoptosis by activating both the death receptor and intrinsic apoptotic pathway. It regulates the cell cycle via down-regulation of cyclins and activation of CDK [14]. In addition, it was reported that butyrate modulates host immune responses by activating neutrophils [15] and enhancing IL-4-dependent IgE production [16]. Butyrate has immune suppression [17] and anti-inflammatory properties, in part by suppressing nuclear factor NF- $\kappa B$ activity [18-20]. Regulation of enzymes involved in cytoskeleton and cell membranes by butyrate has also been reported [21]. The majority of its effects directly result from HDAC inhibition. However, butyrate appears to be involved in signal transduction via its own receptor GPR41, resulting in inosityl 1,4,5-triphosphate generation, intracellular $\mathrm{Ca}^{2+}$ release, ERK1/2 activation, and inhibition of cAMP accumulation [22]. Because of their ability to inhibit cell proliferation, HDAC inhibitors (HDI) including butyrate have been extensively exploited as anti-tumor agents [23]. Butyrate appears to have pleiotropic effects on various biological processes. The genes we identified (see Additional file 1), which fall within a broad range of functional categories, appeared to provide the molecular basis for its pleiotropic effects.

Butyrate seems able to inhibit all class I HDACs [24]. It would be safe to assume that, like trichostatin A (TSA), butyrate can indeed inhibit the activities of HDAC8 and HDAC10, even though butyrate may have a different mechanism of action. Our studies suggested that butyrate indeed repressed histone deacetylase 8 (HDAC8) mRNA expression. The missing link is why this inhibition of enzymatic activities in turn down-regulates their own expression in mRNA levels. In mouse neural cells, it was observed that HDAC inhibitors affect the expression of HDACs themselves [18]. In these cells, both TSA and SB indeed elevated the expression of HDAC1, HDAC3, HDAC5 and HDAC6 whereas mRNA levels of HDAC 2 and HDAC7 did not change. The mRNA levels of HDAC8 and HDAC10 were not detectable in these cells. While the mechanism and biological relevance of HDI regulation of HDAC expression remains unclear, it appears that there indeed exists an auto-regulatory feedback loop to the expression of several HDACs after their activities are inhibited.

It appears that the effects of HDI such as TSA and SB on MMP (matrix metalloproteinase) expression are specific to cell types. In mouse 3T3 fibroblasts, TSA represses MMP2 expression [25], while in human colonic cells DHD/K12, MMP production is inhibited by butyrate [26]. In HT1080 tumor cells, both protein and mRNA levels of TIMP1, TIMP2, MMP2 and MMP9 are increased by butyrate treatment [27]. Based on their data of limited modulation of MMP by butyrate in human SW1116 colon 
Table 3: Comparison of gene expression levels between microarray and real-time RT-PCR

\begin{tabular}{|c|c|c|c|}
\hline Accession & Annotation & Microarray* & Real-time PCR** \\
\hline TC28I450 & BUBI budding uninhibited by benzimidazoles I homolog beta (BUBIB) & 0.1 & 0.1 \\
\hline TC26670I & Fas apoptotic inhibitory molecule (FAIM) & 0.1 & 0.3 \\
\hline TC277820 & MAD2 mitotic arrest deficient-like I variant (MAD2LI) & 0.1 & 0.1 \\
\hline TC26II65 & Centromere protein A (CENPA) & 0.1 & 0.2 \\
\hline TC289876 & Proliferating cell nuclear antigen (PCNA) & 0.1 & 0.1 \\
\hline TC290192 & Spindle pole body component 24 (SPBC24) & 0.1 & 0.2 \\
\hline TC269605 & Hepatocyte growth factor (scatter factor, HGF) & 0.1 & 0.4 \\
\hline TC267353 & Kinesin family member 20A (KIF20A) & 0.1 & 0.1 \\
\hline TC260258 & Proteasome subunit, beta type 8 (PSMB8) & 0.1 & 0.2 \\
\hline TC262855 & Cyclin-dependent kinase 4 (CDK4) & 0.1 & 0.6 \\
\hline TC290639 & Minichromosome maintenance protein 3 associated protein (MCM3AP) & 0.2 & 0.5 \\
\hline TC289874 & Insulin-like growth factor-binding protein 6 (IGFBP6) & 0.2 & 0.3 \\
\hline TC26247I & Heat shock $90 \mathrm{kD}$ protein I, alpha (HSP90AAI) & 0.2 & 0.5 \\
\hline TC295998 & Activator of S phase kinase & 0.3 & 0.3 \\
\hline TC277755 & CSEI chromosome segregation I-like (CSEIL) & 0.3 & 0.4 \\
\hline TC26IIII2 & Profilin I (PFNI) & 0.4 & 0.4 \\
\hline TC294I42 & $\beta$-catenin (CTNNBI) & 1.4 & 5.8 \\
\hline TC260308 & GM2 ganglioside activator protein (GM2A) & 2.3 & 6.6 \\
\hline TC267034 & similar to LIM domain containing 2 (LIMD2) & 2.3 & 4.2 \\
\hline TC292975 & unknown & 2.5 & 17.1 \\
\hline TC276824 & Dual specificity protein phosphatase I (MKP-I) & 2.8 & 6.6 \\
\hline TC260543 & Cathepsin D (CTSD) & 3.0 & 5.1 \\
\hline TC277986 & Cathepsin L precursor (CTSL) & 3.2 & 2.7 \\
\hline TC276574 & Protease, serine, II [IGF binding] (PRSSII) & 3.8 & 11.2 \\
\hline TC298909 & Serine/threonine kinase 32C (STK32C) & 4.3 & 26.2 \\
\hline TC265800 & Activating transcription factor 3 (ATF3) & 4.5 & 10.2 \\
\hline TC277745 & CITED2 & 6.3 & 47.6 \\
\hline TC27674I & Insulin-like growth factor 2 (IGF2) & 6.5 & 100.0 \\
\hline TC2808I5 & Matrix metalloproteinase I3 (MMPI3) & 8.3 & 87.8 \\
\hline TC265993 & Inhibin, beta A (INHBA) & 9.5 & 82.8 \\
\hline
\end{tabular}

* fold change (microarray) = mean background-adjusted, normalized signal intensity from the butyrate treated group divided by mean backgroundadjusted, normalized signal intensity from the control group.

** fold change (real-time PCR): expression in the control group was set at I.0. The values below I.0 indicated down-regulation by butyrate.

cancer cells [28], Emenaker et al suggested that SCFA, such as those derived from dietary fiber, may protect against invasive colon cancer through stimulation of TIMP and inhibition of uPA (plasminogen activator, urokinase) activities rather than their effects on MMP activities. In the present study, we found that both TIMP2 and MMPs, such as MMP1, MMP9 and MMP13, were induced by butyrate. The expression levels of TIMP2 induced by butyrate are similar $(10.82,11.28$, and 14.05 folds, respectively) as detected by the three sequences that represent this gene on the microarray [TIGR: TC260960, TIGR: TC289409 and TIGR: TC289410]. However, changes in MMP levels were not considered significant due to the high stringency cutoff used in this study (FDR $=0 \%$ ). The net effect of this induction on both MMPs and their inhibitor (TIMP2) is still unclear. TIMP2 can promote apoptosis in an in vivo colorectal cancer model yet can protect B16 melanoma cells from apoptosis [29]. The elucidation of the mechanisms involved in controlling these distinctly opposing phenotypic effects of TIMP2 is of paramount importance.
Insulin-like growth factor binding proteins (IGFBP) modulate IGF action and regulate cell growth and apoptosis by preventing IGF from interacting with their own receptors. In our study, insulin-like growth factor (IGF-2) was upregulated by $\mathrm{SB}$, which is consistent with other published data [30]. Our microarray and real-time RT-PCR results confirmed that IGFBP6, which has a 100-fold higher affinity for IGF2 than IGF1 [31], was down-regulated by butyrate. It seems paradoxical that while IGF2 is up-regulated significantly by $\mathrm{SB}$, its highest affinity binding protein is down-regulated. Our results may suggest different functions of various IGFBP members in regulating apoptosis and cell cycle progression. It would be intriguing to see how IGFBP exert their actions in cell growth and apoptosis via an IGF-independent fashion.

Despite the fact that the effect of HDAC inhibitors such as SB on the expression of cell cycle regulatory genes, such as cyclins and cyclin-related kinase (CDK), were documented and a few attempts were made to use high- 


\section{Microarray vs Real-time PCR for 30 Genes}

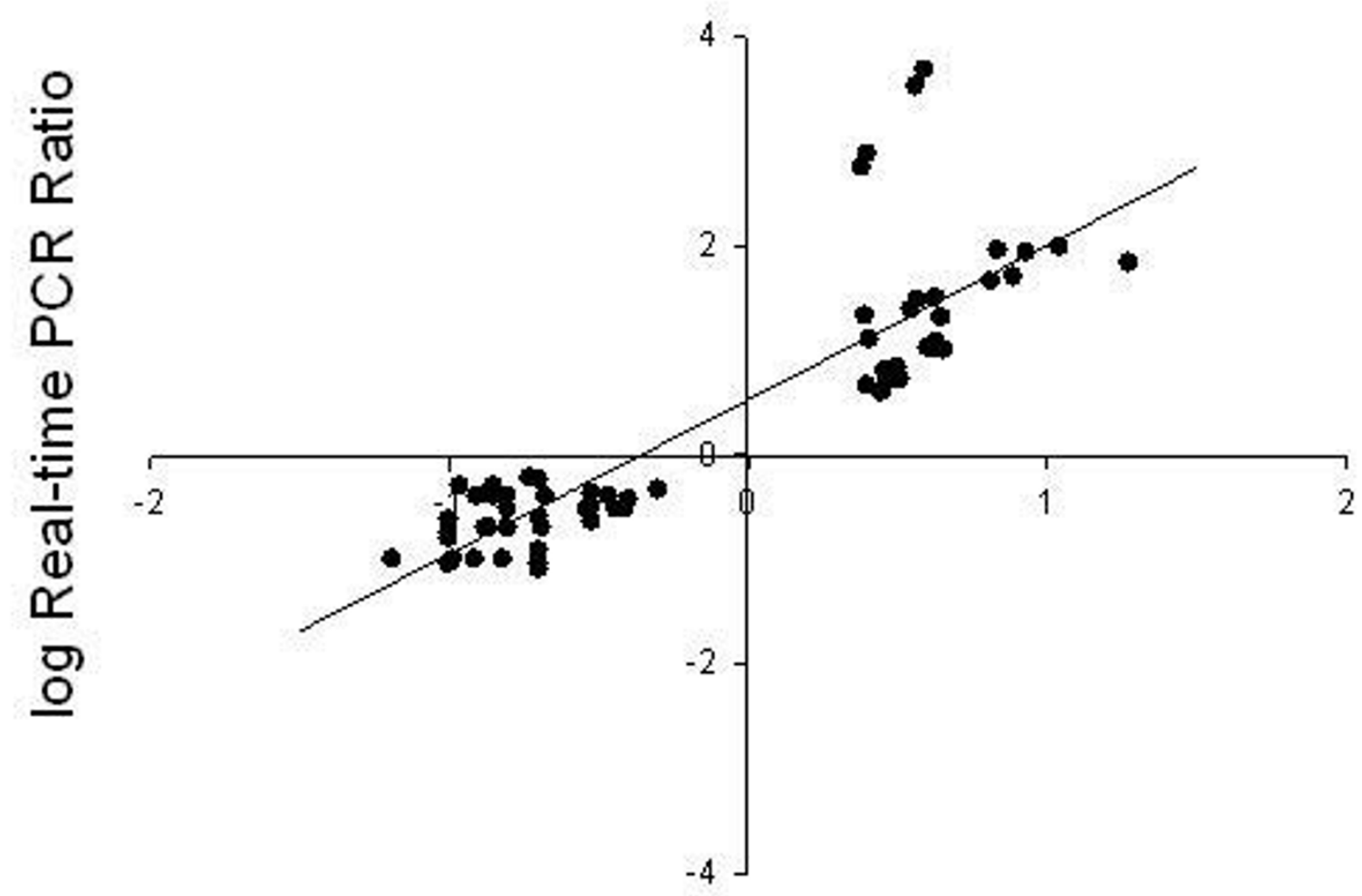

\section{log Microarray Ratio}

\section{Figure 3}

Correlation between levels of gene expression measured by microarray and real-time RT-PCR. The $R=0.867\left(R^{2}=0.76\right)$ was calculated using log-transformed values of the fold change obtained for the 30 selected genes $(n=60)$.

throughput approaches, such as microarrays [6], differential display [32] and SAGE, to study the effects of HDAC inhibitors on cell cycle control, the extent of the effect of these inhibitors on cell proliferation and cell cycle has not been fully realized in part due to limited gene representation on these microarrays $[19,30,33,34]$. Due to significant differences in gene representation, species, microarray platforms, and data analysis tools used in these studies, a direct comparison between our results and those published is seemingly difficult. In general, our results are in good agreement with published reports. For example, we detected $\sim 8 \%$ of all genes were significantly regulated by butyrate in bovine MDBK cells, which is consistent with a previous report [6] in which the authors used cDNA microarray consisting of 8000 sequences to demonstrate that approximately $7 \%$ of sequences assayed exhibited alteration by butyrate in human colon carcinoma cells. Down-regulation of cyclins, PCNA, CDKs, and upregulation of IGF2, MMPs, and TIMP2 were also confirmed by previous reports $[19,34]$. However, many genes, such as Aurora kinases, BUB1 and BUB1B, centromere proteins, kinesins, Max interacting protein 1 (MXI1), minichromosomal maintenance deficient proteins (MCMs), and spindle pole body components were not previously recognized to be regulated by SB. Our efforts in this study are among the first to systematically categorize the butyrate-regulated genes related with cell cycle control with a genome-wide approach in farm animals. While the vast majority of these genes are down-regulated, MXI1 is up-regulated. As a key component of the mitotic checkpoint, MXI1 binds with MAX to form a sequence-specific DNA-binding protein complex and acts 
as a transcriptional repressor. Up-regulation of MXI1 by SB could result in down-regulation of cyclins, which in turn negatively regulates centromere proteins.

Accumulation of cells with 2C and 4C DNA contents suggests inhibition by butyrate of cell cycle at G1 and M/G2 phases and suggests that a common responding element in genes responsive to the treatment of butyrate is required for progression of both phases G1 and M/G2. This observation is also consistent with the previous report that the inhibition of G1 progression by butyrate is not restricted to a specific mitogenic signaling pathway [35], but may also include the inhibitory effect on initiation of DNA replication. In this report, multiple genes such as minichromosome maintenance (MCM) proteins $2,3,4,5$, and 6, as well as Orc1 (Origin Recognition Complex largest subunit) are significantly down-regulated. The products of these genes has been shown to be rate limiting for initiation of DNA replication in eukaryotic cell lines and are essential for the assembly of the pre-replication complex (pre-RC) [36-38]. This finding indicates that in someway, butyrate treatment directly targets these genes and down regulates the genes that are essential for initiation of DNA replication. CDC2/Cdk1 and related cyclins are also significantly down-regulated. At least four roles have now been recognized for cyclin A activated Cdk1 protein kinases in regulating cell cycle events. First, Cdk2/ cyclin A is responsible for activating pre-replication complexes at the beginning of S-phase in order to begin DNA synthesis [39]. Second, Cdk1/cyclin A inhibits assembly of new pre-replication complexes during S-phase [39] by inactivating Cdc6 [40]. Third, Cdk2/cyclin A is required for the G2 to M-phase transition [41]. Finally, Li and DePamphilis [14] recently revealed that Cdk1/cyclin A is required for preventing Orc1 in mammals or ORC in Xenopus from binding to chromatin during mitosis. Our results show that targeted destruction of cdc6 and cdc2/ cdk1 may be involved in the apoptosis and cell cycle arrest induced by butyrate. They are consistent with the growing body of evidence suggesting that disruption of the coordination between regulation of DNA synthesis and cyclindependent kinase activity is an important feature of apoptosis. It is of importance and interest for us to understand the mechanism(s) of how butyrate targets these genes and causes these changes in gene expressions. However, it will require a great deal of efforts and certainly is out of the scope of this report.

Understanding the mechanism of butyrate in affecting apoptosis, cell proliferation and differentiation and especially the difference of its mode of action compared to other HDAC inhibitors will facilitate designing novel and more potent HDAC inhibitors that target specific cellular processes that are dysregulated in neoplastic cells. Dissection of the pathways regulated by butyrate will provide a basis for better utilization of its anti-tumor, anti-metastatic, immune-mediating, and anti-inflammatory properties. In addition, butyrate has been shown to up-regulate transcription levels of muslins, which are the major components of gastrointestinal mucosa considered to be the first line of defense against pathogens [42]. Because of its ability to affect functions of monocyte-derived dendritic cells and macrophage [17] and to activate neutrophils, butyrate and its related biological pathways could be manipulated to fight against gastrointestinal pathogens. Up-regulation of glutathione S-transferases $[43,44]$, genes known to be involved in defense against oxidative stress, by butyrate provides evidence of a favorable modulation of toxicological defense systems. The results presented in this paper not only help to better dissect HDAC inhibition and mechanism in apoptosis and cell cycle control but also help to understand ruminant metabolism and physiology, which in turn could lead to improvement in energy efficiency of cattle.

\section{Conclusion}

The present research identified 450 genes significantly regulated by sodium butyrate in bovine kidney epithelial cells. The genes related to multiple signal pathways such as cell cycle control and apoptosis were presented. The profound changes in gene expression elucidate the molecular basis for the pleiotropic effects of butyrate on biological processes. The results presented in this paper can provide clues on the mechanism of histone deacetylase inhibition by butyrate and resulting alterations in the expression of genes involved in cell cycle, apoptosis, and transcriptional regulation. Since butyrate functions as both a nutrient and signaling molecule regulating the cell growth and proliferation, these findings enable better recognition of the full range of roles butyrate may play during cattle energy metabolism, cell growth and proliferation.

\section{Methods}

\section{Cell Culture and Treatments}

The Madin-Darby bovine kidney epithelial cells (MDBK, American Type Culture Collection, Manassas, VA., Catalog No. CCL-22) were cultured in Eagle's minimal essential medium supplemented with 5\% fetal bovine serum (Invitrogen, Carlsbad, CA) in $25 \mathrm{~cm}^{2}$ flasks with medium renewal twice per week. Cell cultures were maintained in a water-jacked incubator with $5 \% \mathrm{CO}_{2}$ at $37^{\circ} \mathrm{C}$. Sub-cultivations were performed when cells attained 80 to $90 \%$ confluence, according to the product information supplied by American Type Culture Collection. At approximately 50\% confluence (during the exponential phase), the cells were treated with $10 \mathrm{mM}$ of sodium butyrate for $24 \mathrm{~h}$ (Calbiochem, San Diego, CA. Three replicate flasks of cells for both treatment and control groups (a total of 6 samples) were used for the flow cytometry and microarray 
experiments. The harvested cells were snap frozen in liquid $\mathrm{N} 2$ and stored at $-80^{\circ} \mathrm{C}$ until RNA extraction.

\section{Flow Cytometric Analysis of Cells}

The detailed procedures were described in a previous publication [13]. Briefly, cells collected by trypsinization were washed and resuspended in PBS buffer. Two volumes of ice-cold $100 \%$ ethanol were added drop wise into tubes and mixed with cells in suspension by slow vertexing. After incubation with RNase I, cells were then stained with propidium iodide (PI). Measuring the fluorescence by flow cytometry provided a measure of the amount of PI taken up by the cells and, indirectly, the amount of DNA content. Cell DNA content was analyzed using a flow cytometer (FC500, Beckman Coulter, Palatine, IL) and collected data were analyzed using Cytomics RXP (Beckman Coulter). At least 10,000 cells per sample were analyzed.

\section{Preparation of Cell Extracts and Western Blot Analysis}

Preparations of cells and cell extracts, SDS-PAGE and Western Blot analysis were described previously [13]. Briefly, the protein from different samples was separated by SDS PAGE on two identical 4 to $20 \%$ polyacrylamide gradient gels. One gel was stained with SimpleBlue (Invitrogen) and one was transferred to a membrane and probed with monoclonal anti- acetyl-phospho $\mathrm{H} 3$ and anti- acetyl H3 antibodies. The target bands on the Western Blots from three experiments were quantified with a NIH Image software. The relative densities were measured and corrected with the stained protein density.

\section{Isolation of Total RNA}

Total RNA was extracted using Trizol following the manufacturer's recommendations (Invitrogen). Trace genomic DNA in the crude total RNA samples was removed by incubation with 4-10 units DNase I per $100 \mu \mathrm{g}$ total RNA (Ambion, Austin, TX) at $37^{\circ} \mathrm{C}$ for $30 \mathrm{~min}$. Total RNA was further purified using an RNeasy Mini kit (Qiagen, Valenica, CA). The concentration of the total RNA was determined using a NanoDrop ND-1000 spectrophotometer (NanoDrop Technologies, Rockland, DE) and RNA integrity was verified using a Bioanalyzer 1000 (Agilent, Palo Alto, CA).

\section{Generation of Biotin-labeled cRNA}

Biotin-labeled cRNA was generated with a modified procedure of the Superscript Choice System (Invitrogen) for double-strand (ds) cDNA synthesis followed by in vitro transcription. Briefly, the $1^{\text {st }}$ strand cDNA was synthesized from $4.0 \mu \mathrm{g}$ total RNA by 1.0 unit SuperScript II reverse transcriptase (Invitrogen) in the presence of 100 pmoles T7 promoter Oligo dT primer. After $2^{\text {nd }}$ strand synthesis, the DNA was purified with a DNA Clean \& Concentrator5 kit (Zymo Research, Orange, CA) and eluted with 8 to
$16 \mu$ of deionized (dd) $\mathrm{H}_{2} \mathrm{O}$. The recovered ds cDNA was further concentrated down to $3 \mu$ l by a speed vacuum device. cRNA was synthesized with a MEGAscript in vitro Transcription kit (Ambion). The in vitro transcription reaction was carried out in a total volume of $23.0 \mu \mathrm{l}$ consisting of $3.0 \mu \mathrm{l}$ of ds cDNA, $2.3 \mu \mathrm{l} 10 \mathrm{X}$ Ambion reaction buffer, $2.3 \mu \mathrm{l}$ 10X Ambion T7 enzyme mix, and $15.4 \mu \mathrm{l}$ NTP labeling mix (7.5 mM ATP, $7.5 \mathrm{mM}$ GTP, $5.625 \mathrm{mM}$ UTP, $5.625 \mathrm{mM}$ CTP and $1.875 \mathrm{mM}$ biotin-16-UTP and 1.875 $\mathrm{mM}$ biotin-11 CTP). The in vitro transcription reaction was incubated at $37^{\circ} \mathrm{C}$ for $\sim 16$ hours in a thermocycler. The cRNA was purified with an RNeasy mini kit (Qiagen). Generally, 40 to $60 \mu \mathrm{g}$ of cRNA can be obtained from 4.0 $\mu \mathrm{g}$ of input total RNA. The size range of the cRNA, expected to be between 300 to 3000 bp with the maximum intensity centered at least $1000 \mathrm{bp}$, was verified using a Bioanalyzer 1000. The biotinylated cRNA was fragmented to 50 to 200 bp by heating cRNA in a buffer consisting of $40 \mathrm{mM}$ Tris-acetate, $\mathrm{pH} 8.0,100 \mathrm{mM}$ potassium acetate, and $30 \mathrm{mM}$ magnesium acetate at $95^{\circ} \mathrm{C}$ for $35 \mathrm{~min}$.

\section{Oligonucleotide Microarray, Hybridization, Image Acquisition and Data Analysis}

The bovine microarray platform used was described previously [45]. Briefly, a total of 86,191 unique 60mer oligonucleotides were designed and synthesized it in situ using photo deprotection chemistry [46]. Each unique oligonucleotide was repeated 4 times on the array (a total of $\sim 340,000$ features). These oligonucleotides represented 45,383 unique bovine sequences/genes, including 40,808 Tentative Consensus sequences (TCs) from TIGR Bos taurus gene index [47] and 4,575 singletons.

The microarrays were pre-hybridized with $1 \mathrm{X}$ MES hybridization buffer (100 mM MES, $1.0 \mathrm{M} \mathrm{Na}^{+}, 20 \mathrm{mM}$ EDTA, $0.01 \%$ Tween 20$), 40 \mu \mathrm{g}$ herring sperm DNA and $200 \mu \mathrm{g}$ acetylated BSA at $45^{\circ} \mathrm{C}$ for $15 \mathrm{~min}$ followed by hybridization with $10 \mu \mathrm{g}$ denatured and fragmented cRNA per microarray at $45^{\circ} \mathrm{C}$ for $16-20 \mathrm{~h}$ with constant rotation. After hybridization, the microarrays were immediately washed extensively under non-stringent conditions (6x SSPE, $0.01 \%$ Tween 20) at room temperature (RT) followed by a stringent wash (100 mM MES salt and free acid solution, $0.1 \mathrm{M} \mathrm{Na}^{+}, 0.01 \%$ Tween 20 ) at $45^{\circ} \mathrm{C}$. After the final rinse with the non-stringent wash buffer, the microarrays were stained with $1 \times$ Stain buffer (100 mM MES, 1 $\mathrm{M} \mathrm{Na}^{+}, 0.05 \%$ Tween $20,50 \mathrm{mg} / \mathrm{ml}$ of BSA, and $1 \mathrm{mg} / \mathrm{ml}$ of Cy3-streptavidin) at RT for $25 \mathrm{~min}$. The stain buffer was removed and the microarrays were rinsed once more with non-stringent wash buffer. The microarrays were immediately dried under a stream of argon gas and scanned using an Axon GenePix 4000B scanner (Molecular Devices Corp., Union City, CA) at $5 \mu \mathrm{M}$ resolution. The data were extracted from the raw images using NimbleScan software 
(NimbleGen, Madison, WI). The control and butyrate treatment each had 3 replicates and a total of 6 microarrays were used in the experiment (GEO Accession GSE3970). The microarray data are available as accession GSE3970 in the Gene Expression Omnibus repository at the National Center for Biotechnology Information [48].

Relative signal intensities $\left(\log _{2}\right)$ for each feature were generated using the Robust Multi-Array Average (RMA) algorithm $[49,50]$. The data were processed based on quantile normalization method [51] using the R package [52]. This normalization method aims to make the distribution of intensities for each array in a set of arrays the same. The method assumes that a quantile-quantile plot of two data vectors with the same distribution will have a straight diagonal line. The method performed better in dealing with bias and reducing variability across arrays compared to other methods [51]. The background-adjusted, normalized, and log transformed intensity values were then analyzed using the Significance Analysis of Microarrays method [53] with two-class unpaired design (SAM version 2.20 [54]). SAM is the most popular method for microarray analysis with 635 citations of the original publication as of October 2004 [55]. SAM ranks genes based on a modified $t$-test statistic. The unique features of SAM include implementing permutation testing, and the ability to estimate a global false discovery rate (FDR, an expected percentage of false positives among the claimed positives) and a gene error chance ( $q$-value). A sequence was declared to be significant when it met a stringent median false discovery rate (FDR) cutoff at $0 \%$ (see Additional file 1). A BLAST search was conducted for all sequences that met the threshold to remove possible redundancy. When a gene was represented by multiple sequences, the fold change with $q$ value of only one sequence was selected to represent this gene.

\section{Real-time RT-PCR}

Real-time RT-PCR analysis was carried out with the iQ SYBR Green Supermix kit (Biorad) using $200 \mathrm{nM}$ of each amplification primer (see Additional file 2) and the $1^{\text {st- }}$ strand CDNA (80 ng of the input total RNA equivalents) in a $25 \mu \mathrm{l}$ reaction volume. The amplification was carried out on an iCycler $\mathrm{iQ}^{\mathrm{TM}}$ Real Time PCR Detection System (BioRad) with the following profile: $95^{\circ} \mathrm{C}-60$ s; 40 cycles of $94^{\circ} \mathrm{C}-15 \mathrm{~s}, 60^{\circ} \mathrm{C}-30 \mathrm{~s}$, and $72^{\circ} \mathrm{C}-30$ s. The melting curve analysis was performed for each primer pair. Expression levels of $\beta$-actin remained constant (within $0.5 \mathrm{Ct}$ between samples) and were used as endogenous controls. Relative gene expression data were calculated using the $2^{\Delta \Delta C T}$ method [56].

\section{Authors' contributions}

RWL conceived the study, carried out the microarray experiment, provided data analysis, and drafted the man- uscript. CJL cultured the cells, carried out the western blotting and flow cytometry analysis, participated in data mining, and helped to draft the manuscript. Both authors read and approved the final manuscript.

\section{Additional material}

\section{Additional file 1}

Supplementary table 1. This data represents the 466 sequences identified to be significant at FDR $=0 \%$, which represents 450 cattle genes. Click here for file

[http://www.biomedcentral.com/content/supplementary/1471-

2164-7-234-S1.xls]

\section{Additional file 2}

Supplementary table 2. This data represents the forward/reverse primer sequences for the genes selected for real-time PCR confirmation. Click here for file

[http://www.biomedcentral.com/content/supplementary/14712164-7-234-S2.xls]

\section{Acknowledgements}

The authors thank Joy Castano for her excellent technical assistance. Mention of trade names or commercial products in this publication is solely for the purpose of providing specific information and does not imply recommendation or endorsement by the U. S. Department of Agriculture.

\section{References}

I. Miller SJ: Cellular and physiological effects of short-chain fatty acids. Mini Rev Med Chem 2004, 4(8):839-845.

2. Sharp WM, Johnson RR, Owens FN: Ruminal VFA production with steers fed whole or ground corn grain. J Anim Sci 1982 , 55(6): $|505-15| 4$.

3. Emenaker NJ, Calaf GM, Cox D, Basson MD, Qureshi N: Shortchain fatty acids inhibit invasive human colon cancer by modulating uPA, TIMP-I, TIMP-2, mutant p53, Bcl-2, Bax, p2I and PCNA protein expression in an in vitro cell culture model. J Nutr 200 I, I 3 I (I I Suppl):304 IS-6S.

4. Hague A, Paraskeva C: The short-chain fatty acid butyrate induces apoptosis in colorectal tumour cell lines. Eur J Cancer Prev 1995, 4(5):359-364.

5. Chen JS, Faller DV, Spanjaard RA: Short-chain fatty acid inhibitors of histone deacetylases: promising anticancer therapeutics? Curr Cancer Drug Targets 2003, 3(3):219-236.

6. Gassull MA, Cabre E: Nutrition in inflammatory bowel disease. Curr Opin Clin Nutr Metab Care 200I, 4(6):56I-569.

7. Scheppach W, Bartram HP, Richter F: Role of short-chain fatty acids in the prevention of colorectal cancer. Eur J Cancer 1995, 3 I A(7-8): 1077-1080.

8. Johnson IT: Anticarcinogenic effects of diet-related apoptosis in the colorectal mucosa. Food Chem Toxicol 2002, 40(8): II7I- II 178.

9. Dashwood RH, Myzak MC, Ho E: Dietary HDAC inhibitors: time to rethink weak ligands in cancer chemoprevention? Carcinogenesis 2006, 27(2):344-349.

10. Saha RN, Pahan K: HATs and HDACs in neurodegeneration: a tale of disconcerted acetylation homeostasis. Cell Death Differ 2006, I3(4):539-550.

II. Scheppach W, Weiler F: The butyrate story: old wine in new bottles? Curr Opin Clin Nutr Metab Care 2004, 7(5):563-567.

12. Rupnarain C, Dlamini Z, Naicker S, Bhoola K: Colon cancer: genomics and apoptotic events. Biol Chem 2004, 385(6):449-464. 
13. Li C], Elsasser TH: Butyrate-induced apoptosis and cell cycle arrest in bovine kidney epithelial cells: involvement of caspase and proteasome pathways. J Anim Sci 2005, 83(I):89-97.

14. Li C], Vassilev A, DePamphilis ML: Role for CdkI (Cdc2)/cyclin A in preventing the mammalian origin recognition complex's largest subunit (Orcl) from binding to chromatin during mitosis. Mol Cell Biol 2004, 24(I 3):5875-5886.

15. Kasama T, Miwa Y, Isozaki T, Odai T, Adachi M, Kunkel SL: Neutrophil-derived cytokines: potential therapeutic targets in inflammation. Curr Drug Targets Inflamm Allergy 2005 , 4(3):273-279.

16. Yamamoto I, Matsunaga T, Sakata K, Nakamura Y, Doi S, Hanmyou F: Histone hyperacetylation plays a role in augmentation of IL4-induced IgE production in LPS-stimulated murine B-lymphocytes by sodium butyrate. J Biochem (Tokyo) 1996, I I 9(6): |056-106I.

17. Millard AL, Mertes PM, Ittelet D, Villard F, Jeannesson P, Bernard J: Butyrate affects differentiation, maturation and function of human monocyte-derived dendritic cells and macrophages. Clin Exp Immunol 2002, I30(2):245-255

18. Ahmad MS, Krishnan S, Ramakrishna BS, Mathan M, Pulimood AB, Murthy SN: Butyrate and glucose metabolism by colonocytes in experimental colitis in mice. Gut 2000, 46(4):493-499.

19. Joseph J, Mudduluru G, Antony S, Vashistha S, Ajitkumar P, Somasundaram K: Expression profiling of sodium butyrate $(\mathrm{NaB})$ treated cells: identification of regulation of genes related to cytokine signaling and cancer metastasis by $\mathrm{NaB}$. Oncogene 2004, 23(37):6304-63I5.

20. Segain JP, Raingeard de la Bletiere D, Bourreille A, Leray V, Gervois $\mathrm{N}$, Rosales C, Ferrier L, Bonnet C, Blottiere HM, Galmiche JP: Butyrate inhibits inflammatory responses through NFkappaB inhibition: implications for Crohn's disease. Gut 2000, 47(3):397-403.

21. Prasad KN, Sinha PK: Effect of sodium butyrate on mammalian cells in culture: a review. In Vitro 1976, I 2(2): I25-I32.

22. Le Poul E, Loison C, Struyf S, Springael JY, Lannoy V, Decobecq ME, Brezillon S, Dupriez V, Vassart G, Van Damme J, Parmentier M, Detheux M: Functional characterization of human receptors for short chain fatty acids and their role in polymorphonuclear cell activation. J Biol Chem 2003, 278(28):2548I-25489.

23. Piekarz R, Bates S: A review of depsipeptide and other histone deacetylase inhibitors in clinical trials. Curr Pharm Des 2004 I 0(I 9):2289-2298.

24. Bertos NR, Wang AH, Yang XJ: Class II histone deacetylases: structure, function, and regulation. Biochem Cell Biol 200I, 79(3):243-252.

25. Ailenberg M, Silverman M: Differential effects of trichostatin A on gelatinase $A$ expression in $3 \mathrm{~T} 3$ fibroblasts and HT- 1080 fibrosarcoma cells: implications for use of TSA in cancer therapy. Biochem Biophys Res Commun 2003, 302(2): I8I-185.

26. Aparicio A, Gardner A, Tu Y, Savage A, Berenson J, Lichtenstein A: In vitro cytoreductive effects on multiple myeloma cells induced by bisphosphonates. Leukemia 1998, I 2(2):220-229.

27. Zeng $\mathrm{H}$, Briske-Anderson M: Prolonged butyrate treatment inhibits the migration and invasion potential of HTI080 tumor cells. J Nutr 2005, 135(2):29|-295.

28. Emenaker NJ, Basson MD: Short chain fatty acids inhibit human (SW I I I6) colon cancer cell invasion by reducing urokinase plasminogen activator activity and stimulating TIMP-I and TIMP-2 activities, rather than via MMP modulation. J Surg Res 1998, 76(I):41-46.

29. Valente P, Fassina G, Melchiori A, Masiello L, Cilli M, Vacca A, Onisto M, Santi L, Stetler-Stevenson WG, Albini A: TIMP-2 over-expression reduces invasion and angiogenesis and protects $B 16 \mathrm{FIO}$ melanoma cells from apoptosis. Int J Cancer 1998, 75(2):246-253.

30. Chiba T, Yokosuka O, Fukai K, Kojima H, Tada M, Arai M, Imazeki F Saisho $\mathrm{H}$ : Cell growth inhibition and gene expression induced by the histone deacetylase inhibitor, trichostatin $A$, on human hepatoma cells. Oncology 2004, 66(6):48I-49I.

31. Baxter RC, Saunders H: Radioimmunossay of insulin-like growth factor-binding protein-6 in human serum and other body fluids. J Endocrinol 1992, I34(I): I33-139.

32. Basson MD, Liu YW, Hanly AM, Emenaker NJ, Shenoy SG, Gould Rothberg BE: Identification and comparative analysis of human colonocyte short-chain fatty acid response genes. Gastrointest Surg 2000, 4(5):50I-5I2.

33. Mariadason JM, Corner GA, Augenlicht LH: Genetic reprogramming in pathways of colonic cell maturation induced by short chain fatty acids: comparison with trichostatin A, sulindac, and curcumin and implications for chemoprevention of colon cancer. Cancer Res 2000, 60( I6):456|-4572.

34. Tabuchi Y, Takasaki I, Doi T, Ishii Y, Sakai H, Kondo T: Genetic networks responsive to sodium butyrate in colonic epithelial cells. FEBS Lett 2006, 580(13):3035-304I.

35. Charollais RH, Buquet $C$, Mester J: Butyrate blocks the accumulation of CDC2 mRNA in late GI phase but inhibits both the early and late GI progression in chemically transformed mouse fibroblasts BP-A3 I. J Cell Physiol 1990, I45(I):46-52.

36. Sun WH, Coleman TR, DePamphilis ML: Cell cycle-dependent regulation of the association between origin recognition proteins and somatic cell chromatin. Embo J 2002, $21(6):$ | $437-1446$.

37. Li CJ, Bogan JA, Natale DA, DePamphilis ML: Selective activation of pre-replication complexes in vitro at specific sites in mammalian nuclei. J Cell Sci 2000, I I 3 ( Pt 5):887-898.

38. $\mathrm{Li} \mathrm{CJ}$, DePamphilis ML: Mammalian Orcl protein is selectively released from chromatin and ubiquitinated during the S-to$M$ transition in the cell division cycle. Mol Cell Biol 2002, 22(1): $105-116$.

39. Coverley D, Laman H, Laskey RA: Distinct roles for cyclins E and A during DNA replication complex assembly and activation. Nat Cell Biol 2002, 4(7):523-528.

40. Jiang $\mathrm{W}$, Wells $\mathrm{NJ}$, Hunter T: Multistep regulation of DNA replication by Cdk phosphorylation of HsCdc6. Proc Natl Acad Sci U S A 1999, 96(II):6193-6198.

41. Furuno N, den Elzen N, Pines J: Human cyclin $A$ is required for mitosis until mid prophase. J Cell Biol 1999, I47(2):295-306.

42. Gaudier E, Forestier L, Gouyer V, Huet G, Julien R, Hoebler C: Butyrate regulation of glycosylation-related gene expression: evidence for galectin-I upregulation in human intestinal epithelial goblet cells. Biochem Biophys Res Commun 2004 325(3): |044-105|

43. Pool-Zobel BL, Selvaraju V, Sauer J, Kautenburger T, Kiefer J, Richter KK, Soom M, Wolfl S: Butyrate may enhance toxicological defence in primary, adenoma and tumor human colon cells by favourably modulating expression of glutathione S-transferases genes, an approach in nutrigenomics. Carcinogenesis 2005, 26(6): 1064-1076.

44. Ranganna K, Yousefipour Z, Yatsu FM, Milton SG, Hayes BE: Gene expression profile of butyrate-inhibited vascular smooth muscle cell proliferation. Mol Cell Biochem 2003, 254(I-2):2 I-36.

45. Li RW, Meyer MJ, Van Tassel CP, Sonstegard TS, Conner EE, Van Amburgh ME, Boisclair YR, Capuco AV: Identification of estrogen-responsive genes in the parenchyma and fat pad of the bovine mammary gland by microarray analysis. Physiol Genomics 2006 , In press:

46. Singh-Gasson S, Green RD, Yue Y, Nelson C, Blattner F, Sussman MR, Cerrina F: Maskless fabrication of light-directed oligonucleotide microarrays using a digital micromirror array. Nat Biotechnol 1999, I 7(10):974-978.

47. TIGR [http://www.tigr.org]

48. National Center for Biotechnology Information [http:// www.ncbi.nlm.nih.gov/geo]

49. Irizarry RA, Hobbs B, Collin F, Beazer-Barclay YD, Antonellis KJ, Scherf U, Speed TP: Exploration, normalization, and summaries of high density oligonucleotide array probe level data. Biostatistics 2003, 4(2):249-264.

50. Irizarry RA, Bolstad BM, Collin F, Cope LM, Hobbs B, Speed TP. Summaries of Affymetrix GeneChip probe level data. Nucleic Acids Res 2003, 3 I(4): el5.

5I. Bolstad BM, Irizarry RA, Astrand M, Speed TP: A comparison of normalization methods for high density oligonucleotide array data based on variance and bias. Bioinformatics 2003 19(2): 185-193.

52. Bioconductor [http://www.bioconductor.org]

53. Tusher VG, Tibshirani R, Chu G: Significance analysis of microarrays applied to the ionizing radiation response. Proc Nat Acad Sci U S A 2001, 98(9):51 | 6-5I 21 .

54. Department of Statistics-Stanford University [http:// www.stat.stanford.edu/ntibs/clickwrap/sam] 
55. Larsson $O$, Wahlestedt C, Timmons JA: Considerations when using the significance analysis of microarrays (SAM) algorithm. BMC Bioinformatics 2005, 6(I): 129.

56. Livak KJ, Schmittgen TD: Analysis of relative gene expression data using real-time quantitative PCR and the 2(-Delta Delta C(T)) Method. Methods 200I, 25(4):402-408.

Publish with Bio Med Central and every scientist can read your work free of charge

"BioMed Central will be the most significant development for disseminating the results of biomedical research in our lifetime. " Sir Paul Nurse, Cancer Research UK

Your research papers will be:

- available free of charge to the entire biomedical community

- peer reviewed and published immediately upon acceptance

- cited in PubMed and archived on PubMed Central

- yours - you keep the copyright

Submit your manuscript here:

http://www.biomedcentral.com/info/publishing_adv.asp
BioMedcentral 